\title{
WYE-354 restores Adriamycin sensitivity in multidrug-resistant acute myeloid leukemia cell lines
}

\author{
SARA M. IBRAHIM ${ }^{1}$, SHERIN BAKHASHAB ${ }^{1,2}$, ASAD M. ILYAS ${ }^{1}$, PETER N. PUSHPARAJ $^{2,4}$, SAJJAD KARIM $^{2,4}$, \\ JALALUDDIN A. KHAN $^{1}$, ADEL M. ABUZENADAH ${ }^{2-4}$, ADEEL G. CHAUDHARY ${ }^{2,4,5}$, \\ MUHAMMED H. AL-QAHTANI ${ }^{2,4}$ and FARID AHMED ${ }^{2,4}$ \\ ${ }^{1}$ Department of Biochemistry, Faculty of Science; ${ }^{2}$ Center of Excellence in Genomic Medicine Research; \\ ${ }^{3}$ King Fahd Medical Research Center; ${ }^{4}$ Faculty of Applied Medical Sciences; \\ ${ }^{5}$ Center for Innovative Technology in Personalized Medicine, King Abdulaziz University, Jeddah 21589, Saudi Arabia
}

Received October 15, 2018; Accepted March 5, 2019

DOI: $10.3892 /$ or.2019.7093

\begin{abstract}
Multidrug resistance (MDR) is a major reason for the failure of acute myeloid leukemia (AML) therapy. Agents that reverse MDR and sensitize AML cells to chemotherapy are of great clinical significance. The present study developed Adriamycin (Adr)-resistant cell lines, namely K562/Adr200 and K562/Adr500, which exhibited MDR. The upregulation of ATP-binding cassette subfamily B member 1 (ABCB1) was confirmed as the mechanism of resistance by reverse transcription-quantitative polymerase chain reaction and western blot analyses. Subsequently, the role of the mammalian target of rapamycin (mTOR) kinase inhibitor, WYE-354, in sensitizing the K562/Adr200 and K562/Adr500 cell lines to Adr was evaluated. At sub-cytotoxic concentrations, WYE-354 increased Adr cytotoxicity in the K562/Adr200 and K562/Adr500 cells. WYE-354 restored Adr sensitivity in the resistant cells by inhibiting ABCB1-mediated substrate efflux, thereby leading to an accumulation of Adr, an increase in Adr-mediated G2/M cell cycle arrest and the induction of apoptosis. Furthermore, WYE-354 stimulated the ATPase activity of ABCB1, which was consistent with in silico predictions using a human ABCB1 mouse homology model, indicating that WYE-354 is a potent substrate of ABCB1. WYE-354 did not regulate the expression of ABCB1 at the concentrations used in the present study. These findings indicate that WYE-354 may be a competitive inhibitor of ABCB1-mediated efflux and a potential candidate in combination with standard chemotherapy for overcoming MDR. Further clinical investigations are warranted to validate this combination in vivo.
\end{abstract}

Correspondence to: Dr Farid Ahmed, Center of Excellence in Genomic Medicine Research, King Abdulaziz University, PO Box 80216, Jeddah 21589, Saudi Arabia

E-mail: fahmed1@kau.edu.sa

Key words: multidrug resistance, ATP-binding cassette subfamily B member 1, WYE-354, mammalian target of rapamycin inhibitors, acute myeloid leukemia

\section{Introduction}

The treatment of acute myeloid leukemia (AML) is hampered by the development of resistance to chemotherapy. Multidrug resistance (MDR) is a phenomenon by which cancer cells become simultaneously resistant to several structurally and functionally distinct molecules, rendering them ineffective. Resistance to anticancer therapy can arise via different contributing mechanisms, including metabolic inactivation of drugs, alteration of drug targets, increased drug efflux, evasion of cell death, increased repair of damaged DNA, epithelial-mesenchymal transition, and epigenetic mechanisms including DNA methylation and histone modification $(1,2)$. Cancer cell heterogeneity and the tumor microenvironment are also involved in the development of acquired resistance to chemotherapeutics (3). Drug efflux is an evolutionarily conserved mechanism observed in microbes, which is also exhibited by cancer cells. The efflux of substrates is an important protective mechanism in normal cell physiology, which prevents the accumulation of toxins and is an integral property of the blood-brain barrier (4).

Members of the ATP-binding cassette (ABC) transporters serve a key role in mediating the extracellular pumping of substrates (5). ABC subfamily B member 1 (ABCB1) is the first member of the ABC superfamily of transporters to be implicated in MDR (6). Structurally, it consists of two homologous arms, each comprising six transmembrane domains connected to an ATP-binding domain via flexible polypeptide linkers. ABCB1 substrates include an array of hydrophobic compounds, including anthracyclines, Vinca alkaloids, epipodophyllotoxins, taxanes and several tyrosine kinase inhibitors (7). The inhibition of ABCB1-mediated drug efflux is a relevant therapeutic approach for overcoming MDR (8). In this regard, several generations of $\mathrm{ABCB} 1$ inhibitors have been developed but have failed to produce the desired clinical response and are associated with systemic toxicity. Therefore, there is an urgent requirement for agents capable of modulating the activity of $\mathrm{ABCB} 1$ and producing therapeutically relevant inhibition without exerting adverse effects. Small molecule inhibitors, such as alectinib, bafetinib, trametinib and quizartinib, which target specific molecules in oncogenic 
signaling, have been reported to modulate ABC pumps and reverse resistance by acting as substrates/inhibitors (9-12).

The phosphoinositide 3-kinase (PI3K)/AKT/mammalian target of rapamycin (mTOR) signaling pathway constitutes the central axis of intracellular growth signaling, which is commonly deregulated in cancer. In total, $50-70 \%$ of patients with AML exhibit abnormal/hyperactivated PI3K signaling (13). The therapeutic inhibition of mTOR has resulted in anticancer effects in vitro and in vivo in various cancer types, including AML. Several mTOR inhibitors have been approved by the USA Food and Drug Administration and are currently used as a single agent or in combination (14-17). Furthermore, inhibitors of mTOR have been demonstrated to overcome chemoresistance (18-20). Classical mTOR inhibitors, including rapamycin and its analogs (rapalogs), are only modestly effective as anticancer agents as they only partially suppress the PI3K/AKT/mTOR signaling pathway, leading to a compensatory overactivation of the pathways via a negative feedback loop (21). The mechanistic insufficiency of rapalogs in completely deactivating PI3K signaling is overcome by a novel class of ATP-competitive mTOR inhibitors that target the kinase domain of mTOR, thereby effectively repressing mTOR complex (mTORC) 1 and mTORC2 (22). WYE-354 is a synthetic mTOR kinase inhibitor, which has demonstrated robust anticancer activity via dual inhibition of the mTORC1 and mTORC2 complexes in several cell lines (23-25). The present study evaluated WYE-354 as a potent chemosensitizing agent and assessed its role in reversing MDR mediated by ABCB1. Furthermore, the present study attempted to elucidate the mechanisms by which WYE-354 causes chemosensitization and aimed to understand its interaction with the ABCB1 protein using in silico methods.

\section{Materials and methods}

Cell culture and reagents. The Adriamycin (Adr)-resistant cell lines K562/Adr200 and K562/Adr500 were generated by culturing K562 cells (CLS Cell Lines Service GmbH, Eppelheim, Germany) in step-wise incremental doses of Adr, ranging between 0.002 and $0.5 \mu \mathrm{M}$ over a period of 2 months at $37^{\circ} \mathrm{C}$ with $5 \% \mathrm{CO}_{2}$ in a humidified incubator. Resistant clones were selected upon plating of the cells in methylcellulose semi-solid medium (MethoCult ${ }^{\mathrm{TM}}$ H4230; Stemcell Technologies, Inc., Vancouver, BC, Canada). The resistant cells were maintained without Adr for $>2$ weeks prior to experimentation. The cells were cultured in RPMI medium supplemented with $10 \%$ fetal bovine serum and ciprofloxacin $(10 \mu \mathrm{g} / \mathrm{ml})$ and were maintained at $37^{\circ} \mathrm{C}$ with $5 \% \mathrm{CO}_{2}$ in a humidified incubator. All cell culture reagents were purchased from Thermo Fisher Scientific, Inc. (Waltham, MA, USA).

Adr, daunorubicin, idarubicin, etoposide and WYE-354 were purchased form Selleck Chemicals (Houston, TX, USA). Verapamil and cisplatin were purchased from Merck KGaA (Darmstadt, Germany). The CellTiter ${ }^{\circledR}$-Blue Cell Viability assay was acquired from Promega Corporation (Madison, WI, USA). The RNeasy Mini kit was purchased from Qiagen $\mathrm{GmbH}$ (Hilden, Germany). The SuperScript VILO cDNA Synthesis kit was acquired from Thermo Fisher Scientific, Inc. and Power SYBR ${ }^{\circledR}$-Green PCR Master Mix was from Applied Biosystems; Thermo Fisher Scientific, Inc. The primers used to amplify ABCB1 and GAPDH were purchased from Metabion International AG (Planegg, Germany). Mammalian Cell Lysis kit was obtained from Sigma-Aldrich; Merck KGaA. Protein concentration was determined using the DC Protein Assay Reagents Package from Bio-Rad Laboratories, Inc. (Hercules, CA, USA). NuPAGE ${ }^{\circledR}$ gels and buffers, in addition to the Invitrogen WesternBreeze ${ }^{\mathrm{TM}}$ chemiluminescent kit for western blotting, were purchased from Thermo Fisher Scientific, Inc. The antibody against ABCB1 (cat. no. MA-126529) was obtained from Thermo Fisher Scientific, Inc., whereas anti- $\beta$-tubulin (cat. no. MAB8527), anti-human phosphorylated (p)-p70S6K (T389) (cat. no. MAB8963) and anti-p70S6K (cat. no. MAB8962) antibodies were purchased from R\&D Systems, Inc. (Minneapolis, MN, USA). The Pgp-Glo ${ }^{\mathrm{TM}}$ assay system was purchased from Promega Corporation. The BD Pharmingen APC-Annexin V kit from BD Biosciences (San Jose, CA, USA) was used for the analysis of apoptosis.

Cell viability assay. The cells $\left(10^{4} /\right.$ well) were incubated with a concentration gradient of chemotherapeutic drugs ranging from 0.01 to $100 \mu \mathrm{M}$, alone or in combination with WYE-354 $(0.2$ or $1 \mu \mathrm{M})$ or Verapamil $(5 \mu \mathrm{M})$ in 96 -well plates for $48 \mathrm{~h}$ at $37^{\circ} \mathrm{C}$. Subsequently, $20 \mu \mathrm{l}$ CellTiter ${ }^{\circledR}$-Blue Cell Viability reagent was added to each well and incubated for an additional $2 \mathrm{~h}$ for the development of fluorescence. The fluorescence emission was measured at $590 \mathrm{~nm}$ using the SpectraMax ${ }^{\circledR} \mathrm{i} 3 \mathrm{x}$ Multi-Mode microplate reader (Molecular Devices, LLC, San Jose, CA, USA) and plotted against drug concentrations to determine the mean inhibitory concentration of the drug combination producing $50 \%$ decrease in cell viability $\left(\mathrm{IC}_{50}\right)$.

Adr accumulation assay. The cells $\left(10^{5}\right)$ were counted, seeded in a 6-well plate and incubated with $10 \mu \mathrm{M}$ Adr for $2 \mathrm{~h}$ at $37^{\circ} \mathrm{C}$ to allow drug uptake to occur. Subsequently, the cells were washed twice with $1 \mathrm{X}$ ice-cold PBS and immediately analyzed on a BD FACSAria III (BD Biosciences). Adr florescence was measured using the 561-nm excitation laser line and the emission was acquired using a 582/15-nm filter. A minimum of 10,000 events were acquired for analysis.

Reverse transcription-quantitative polymerase chain reaction $(R T-q P C R)$ analysis. Primer-BLAST (National Center for Biotechnology Information; National Institutes of Health, Bethesda, MD, USA) was used to design primer oligonucleotide sequences for the ABCB1 gene. The messenger RNA (mRNA) expression levels of ABCB1 were determined using the following forward and reverse primer sequences, respectively: 5'-TTGCTG CTTACATTCAGGTTTCA-3' and 5'-AGCCTATCTCCGTC GCATT-3'. The primer pair used for GAPDH was forward, 5'-TGAAGGTGCCATCATTCTTG-3' and reverse, 5'-ATGAGC GACGTGGCTATTGT-3'. RNA (100 ng) was used to prepare cDNA using the SuperScript ${ }^{\circledR}$ VILO $^{\mathrm{TM}}$ cDNA synthesis kit as per manufacturer's instructions. RT-qPCR was performed using $1 \mu \mathrm{l}$ cDNA in a $20 \mu \mathrm{l}$ reaction mix containing $10 \mu \mathrm{l}$ Power SYBR $^{\circledR}$-Green PCR Master mix and $100 \mathrm{nM}$ each of forward and reverse primers. Amplifications were performed under following conditions: $95^{\circ} \mathrm{C}$ for $20 \mathrm{sec}$, followed by 40 cycles of $95^{\circ} \mathrm{C}$ for $15 \mathrm{sec}, 60^{\circ} \mathrm{C}$ for $60 \mathrm{sec}$ and $72^{\circ} \mathrm{C}$ for $15 \mathrm{sec}$. Data was collected at the end of the extension step $\left(72^{\circ} \mathrm{C}\right)$. Melt curve analysis was performed to ensure specificity of the amplified 
product. Relative gene expression was calculated by the $2^{-\Delta \Delta \mathrm{Cq}}$ method (26).

Western blot analysis. Total protein was extracted with RIPA lysis buffer containing protease and phosphatase inhibitor cocktails (cat. nos. sc-24948 and sc-45044 respectively; Santa Cruz Biotechnology, Inc., Dallas, TX, USA) and quantified using the DC ${ }^{\text {тм }}$ Protein assay (Bio-Rad Laboratories, Inc.) according to the manufacturer's protocol. A total of $\sim 40 \mu \mathrm{g}$ protein sample was prepared under reducing conditions with the NuPAGE reducing agent (Thermo Fisher Scientific, Inc.) at $37^{\circ} \mathrm{C}$ for $30 \mathrm{~min}$ and loaded onto $4-12 \%$ NuPAGE gradient gels for electrophoresis, which was performed at $200 \mathrm{~V}$ for $2 \mathrm{~h}$. The transfer onto a methanol-activated 0.45-micron PVDF membrane (Thermo Fisher Scientific, Inc.) was conducted overnight at $30 \mathrm{~V}$ and $4^{\circ} \mathrm{C}$ with a transfer buffer containing $0.1 \%$ SDS. Subsequently, the membrane was washed, blocked for $60 \mathrm{~min}$ at room temperature using buffers supplied with the WesternBreeze ${ }^{\mathrm{TM}}$ Chemiluminescent kit and probed with anti-ABCB1 (dilution 1:200), anti- $\beta$-tubulin (dilution 1:1,000), anti-p-p70S6K (dilution 1:1,000) or anti-p70S6K (dilution 1:4,000) antibodies overnight at $4^{\circ} \mathrm{C}$. The primary antibody was completely removed by washing and the membrane was re-incubated with the secondary antibody from the WesternBreeze ${ }^{\mathrm{TM}}$ Chemiluminescent kit for $60 \mathrm{~min}$ at room temperature. The chemiluminescent agent from the WesternBreeze ${ }^{\mathrm{TM}}$ Chemiluminescent kit was applied upon washing the membrane several times, and the reaction was allowed to develop for $5 \mathrm{~min}$ prior to acquisition of the results on a C-DiGit Blot Scanner (LI-COR Biosciences, Lincoln, NE, USA). Western blot images were analyzed using Image Studio Digits version 4.0 (LI-COR Biosciences).

Cell cycle analysis. The cells $\left(3.5 \times 10^{5}\right)$ were incubated with the corresponding drugs at $37^{\circ} \mathrm{C}$ for $72 \mathrm{~h}$. Subsequently, the cells were collected and washed twice with ice-cold PBS (1X). The washed cells were fixed on ice for 20 min using a fixation buffer containing paraformaldehyde. Hoechst $33342(10 \mu \mathrm{g} / \mathrm{ml}$; Thermo Fisher Scientific, Inc.) was used for staining. The cells were then incubated in the dark for $30 \mathrm{~min}$ on ice. A total of 20,000 events were acquired using a BD FACSAria III. FlowLogic version 7.2.1 software (Inivai Technologies, Victoria, Australia) was used to obtain the percentages of cells in the G1, S and G2/M phases in the singlet-gated population.

Apoptosis assay. The cells $\left(1.5 \times 10^{5}\right)$ were counted and plated in a 12 -well plate. Following $48 \mathrm{~h}$ of drug treatment, the cells were harvested and washed twice with PBS (1X). APC-Annexin V and 7-AAD (both from BD Biosciences) were added to the cell suspension according to the manufacturer's protocol. The cells were mixed gently on a vortex and incubated in the dark for $20 \mathrm{~min}$ at room temperature. The labelled cells were analyzed by acquiring 10,000 events using a BD FACSAria III.

Rhodamine 6G (R6G) efflux assay. The cells $\left(10^{5}\right)$ were counted and suspended in $1 \mathrm{ml}$ RPMI medium. R6G $(0.5 \mu \mathrm{M})$ was added to the medium alongside 1,5 or $10 \mu \mathrm{M}$ WYE-354, or $100 \mu \mathrm{M}$ Verapamil as control inhibitors and incubated for $60 \mathrm{~min}$ at $37^{\circ} \mathrm{C}$. Upon dye uptake, the cells were pelleted by centrifugation at $250 \mathrm{xg}$ for $5 \mathrm{~min}$ at $4^{\circ} \mathrm{C}$ in a cold centrifuge.
The harvested cells were washed twice with $1 \mathrm{X}$ ice-cold PBS and resuspended in $1 \mathrm{ml}$ RPMI with the inhibitors alone, and reincubated for an additional $60 \mathrm{~min}$ at $37^{\circ} \mathrm{C}$ to allow the efflux of R6G. The cells were subsequently washed twice with ice-cold PBS and analyzed immediately on a BD FACSAria III. A minimum of 5,000 events were recorded for analysis.

ABCB1-ATPase assay. The ABCB1-ATPase assay was performed using the Pgp-Glo ${ }^{\mathrm{TM}}$ assay system. Briefly, recombinant human ABCB1 (hABCB1)-containing membranes were incubated with different concentrations of WYE-354 and $0.25 \mathrm{mM}$ sodium orthovanadate in the presence of $5 \mathrm{mM} \mathrm{MgATP}$ at $37^{\circ} \mathrm{C}$ for $40 \mathrm{~min}$. The unconsumed ATP was quantified by adding ATP detection buffer, and luminescence was recorded after $20 \mathrm{~min}$ at room temperature using a SpectraMax ${ }^{\circledR}$ i3x Multi-Mode microplate reader. The basal and drug-stimulated ABCB1-ATPase activities were calculated according to the manufacturer's protocol.

Docking analysis. The three-dimensional structure of the ligand was generated from PubChem and Balloon (https://pubchem. ncbi.nlm.nih.gov/ and http://users.abo.fi/mivainio/balloon/index. php). BLASTp and HHBlits (https://blast.ncbi.nlm.nih.gov/Blast. cgi?PAGE=Proteins;https://toolkit.tuebingen.mpg.de/\#/tools/hhblits) were used to interrogate the human ABCB1 (UniProt ID: P08381) amino acid sequence against the SWISS-MODEL (https://swissmodel.expasy.org/) template library. Based on the target-template alignment, hABCB1 mouse homology models were established using Promod3. CLC Drug Discovery Workbench 4.0 (Qiagen $\mathrm{GmbH}$ ) was used for docking. Based on the binding scores, the top 100 binding conformations were selected and analyzed.

Statistical analysis. All statistical analyses were performed using GraphPad Prism Software version 6.07 (GraphPad Software, Inc., La Jolla, CA, USA). Student's t-test was used to compare paired data points between each group. $\mathrm{P}<0.05$ over a $95 \%$ confidence interval was considered to indicate a statistically significant difference.

\section{Results}

Adr-resistant cell lines exhibit $M D R$ and overexpress $A B C B 1$. In order to screen agents capable of reversing ABCB1-mediated resistance, the present study first developed Adr-resistant K562 cells exhibiting varying levels of resistance. The cell viability assay revealed 16 -fold differences in $\mathrm{IC}_{50}$ values in the $\mathrm{K} 562 / \mathrm{Adr} 200$ cells and 30-fold differences in $\mathrm{IC}_{50}$ values in the K562/Adr500 cells compared with the parental cells (Fig. 1A). Additionally, the K562/Adr200 and K562/Adr500 cells exhibited varying degrees of resistance to other chemotherapeutics (daunorubicin, idarubicin and etoposide), demonstrating the establishment of MDR cell lines (Fig. 1B-D and Table I). To clarify the mechanism of MDR, the intracellular Adr concentration was quantified by determining Adr fluorescence levels in the parental and the two resistant cell lines using flow cytometry. As shown in Fig. 1E, Adr fluorescence was considerably reduced in the K562/Adr200 and K562/Adr500 cells compared with the parental K562 cells. The RT-qPCR analysis revealed increased mRNA levels of ABCB1 by 70 and 148-fold in the K562/Adr200 and K562/Adr500 cells, 
Table I. $\mathrm{IC}_{50}$ values of chemotherapeutics.

\begin{tabular}{lccc}
\hline & \multicolumn{3}{c}{$\mathrm{IC}_{50} \mu \mathrm{M}(\mathrm{RR})$} \\
\cline { 2 - 4 } Drug & $\mathrm{K} 562$ & $\mathrm{~K} 562 / \mathrm{Adr} 200$ & $\mathrm{~K} 562 /$ Adr500 \\
\hline Adriamycin & $0.153 \pm 0.011$ & $2.506 \pm 0.304(16.379)^{\mathrm{b}}$ & $4.659 \pm 0.786(30.451)^{\mathrm{b}}$ \\
Daunorubicin & $0.167 \pm 0.011$ & $0.972 \pm 0.523(5.834)$ & $2.026 \pm 0.283(12.163)^{\mathrm{b}}$ \\
Idarubicin & $0.070 \pm 0.004$ & $0.174 \pm 0.126(2.470)$ & $0.255 \pm 0.089(3.627)^{\mathrm{a}}$ \\
Etoposide & $2.391 \pm 0.071$ & $5.193 \pm 0.155(2.172)^{\mathrm{b}}$ & $7.892 \pm 2.658(3.301)^{\mathrm{b}}$ \\
Cisplatin & $12.821 \pm 0.86$ & $11.942 \pm 1.71(0.93)$ & $12.390 \pm 1.49(0.97)$ \\
\hline
\end{tabular}

Data are presented as the mean \pm standard deviation of three independent experiments performed in triplicate. RR was calculated by dividing the $\mathrm{IC}_{50}$ of the drug in the resistant cells by that in the parental cells. ${ }^{\mathrm{a}} \mathrm{P}<0.05$ and ${ }^{\mathrm{b}} \mathrm{P}<0.005$ vs. $\mathrm{K} 562$ control. $\mathrm{IC}_{50}$, concentration producing $50 \%$ decrease in cell viability; $R R$, relative resistance.

A

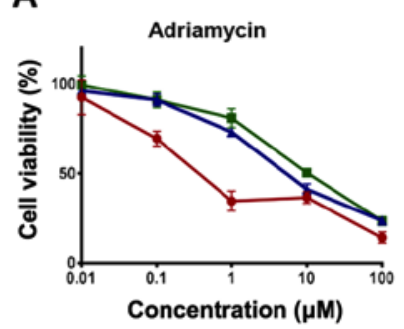

E

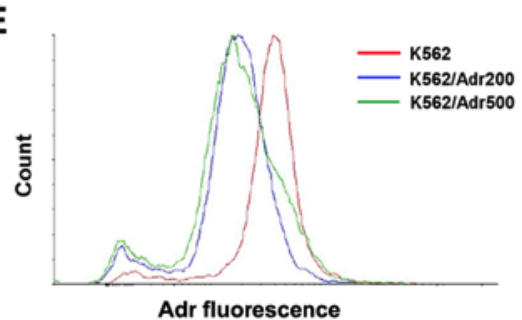

B

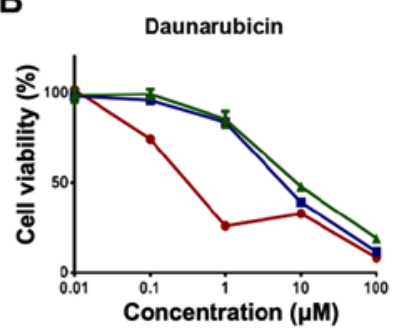

$\mathbf{F}$

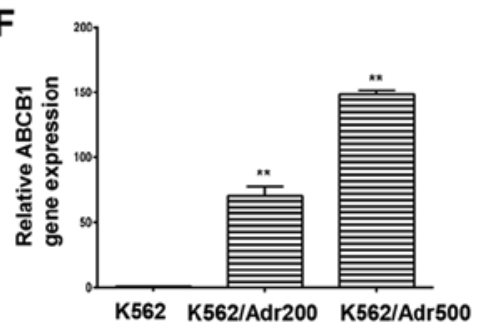

C
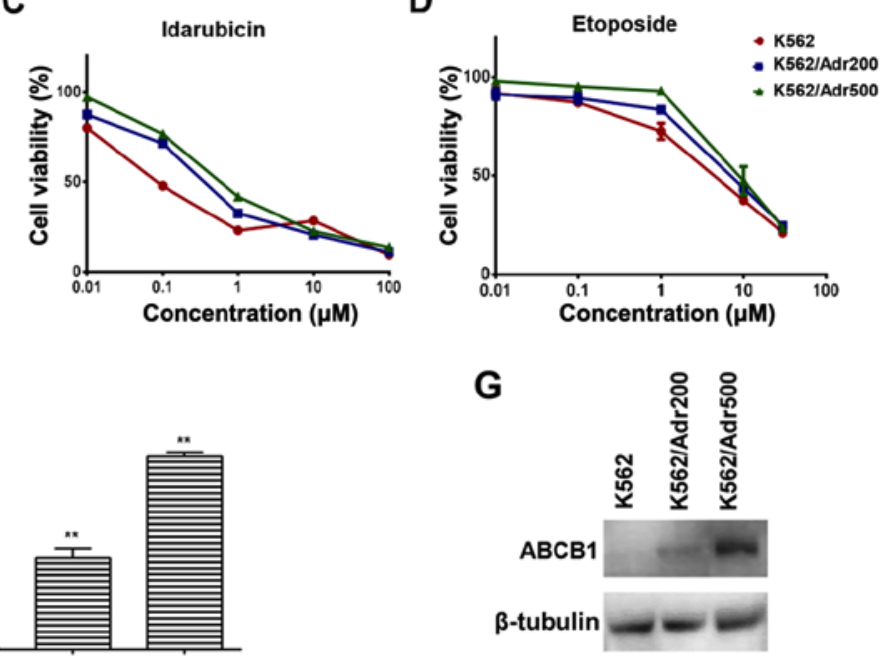

Figure 1. Dose-response curves of K562, K562/Adr200 and K562/Adr500 cells to drug treatment. Dose-response curves of cells treated with increasing concentrations of (A) Adr, (B) daunorubicin, (C) idarubicin and (D) etoposide for $48 \mathrm{~h}$ demonstrating different fold resistance. (E) Adr florescence in K562/Adr200 and K562/Adr500 cells was decreased compared with that in K562 cells following exposure to $10 \mu \mathrm{M}$ Adr for $2 \mathrm{~h}$. (F) Reverse transcription-quantitative polymerase chain reaction analysis revealed increased mRNA levels of ABCB1 in K562/Adr200 and K562/Adr500 cells. (G) Western blot showing increased protein expression of ABCB1 in K562/Adr200 and K562/Adr500 cells. ${ }^{*} \mathrm{P}<0.005$ compared with K562. Adr, adriamycin; ABCB1, ATP-binding cassette subfamily B member 1 .

Table II. Comparison of average $\mathrm{Cq}$ values for $\mathrm{ABCB} 1$ and GAPDH using SYBR-Green reverse transcription-quantitative polymerase chain reaction analysis.

\begin{tabular}{lcc}
\hline Cell line & ABCB1 Cq value & GAPDH Cq value \\
\hline K562 & $26.45 \pm 0.08$ & $18.57 \pm 0.28$ \\
K562/Adr200 & $20.25 \pm 0.06$ & $18.53 \pm 0.20$ \\
K562/Adr500 & $19.54 \pm 0.26$ & $19.12 \pm 0.22$ \\
\hline
\end{tabular}

Cq values are presented as the mean \pm standard deviation. $\mathrm{ABCB} 1$, ATP-binding cassette subfamily B member 1 .

respectively (Fig. 1F and Table II). Increased protein levels of ABCB1 were also confirmed by western blot analysis (Fig. 1G). The resistant cells did not show increased expression of
ABCG2, also known to efflux Adr (data not shown). In addition, the cytotoxicity of cisplatin, which is not an ABCB1 substrate, did not differ between parental and resistant cells (Table I). Therefore, the overexpression of ABCB1 was recognized as the underlying mechanism for the observed MDR.

WYE-354 increases Adr cytotoxicity in Adr-resistant cell lines. WYE-354 cytotoxicity (Fig. 2A) was first determined in the parental K562 and resistant cell lines K562/Adr200 and K562/Adr500 using the CellTiter ${ }^{\circledR}$-Blue Cell Viability assay. Based on the $\mathrm{IC}_{50}$ of WYE-354 in the parental and resistant cell lines ( $>3.2 \mu \mathrm{M}$; Fig. 2B), two doses of WYE-354 (0.2 and $1 \mu \mathrm{M}$ ), producing $<10$ and $<30 \%$ cell death respectively, were selected for examining Adr sensitivity in the K562/Adr200 and K562/Adr500 cells. As shown in Fig. 2C-E, $0.2 \mu$ M WYE-354 produced a marginal decrease in $\mathrm{Adr} \mathrm{IC}_{50}$ in the $\mathrm{K} 562 / \mathrm{Adr} 200$ cells, with a significant decrease in $\mathrm{Adr} \mathrm{IC}_{50}$ observed for the K562/Adr500 cells. The addition of $1 \mu \mathrm{M}$ WYE-354 
Table III. Adr $\mathrm{IC}_{50}$ values in the presence of indicated doses of WYE-354.

\begin{tabular}{llll}
\hline & & $\mathrm{IC}_{50} \mu \mathrm{M}(\mathrm{FR})$ & \\
\cline { 2 - 4 } Drug & \multicolumn{1}{c}{$\mathrm{K} 562$} & $\mathrm{~K} 562 / \mathrm{Adr} 200$ & $\mathrm{~K} 562 / \mathrm{Adr} 500$ \\
\hline Adriamycin & $0.153 \pm 0.011(1.000)$ & $2.506 \pm 0.304(16.379)$ & $4.659 \pm 0.786(30.451)$ \\
$+0.2 \mu \mathrm{M}$ WYE-354 & $0.124 \pm 0.09(0.810)$ & $2.230 \pm 0.661(14.575)$ & $2.879 \pm 0.381(18.816)^{\mathrm{a}}$ \\
$+1 \mu \mathrm{M}$ WYE-354 & $0.110 \pm 0.238(0.718)$ & $1.358 \pm 0.279(8.875)^{\mathrm{a}}$ & $1.778 \pm 0.391(11.620)^{\mathrm{a}}$ \\
$+5 \mu \mathrm{M}$ verapamil & $0.109 \pm 0.053(0.712)$ & $1.683 \pm 0.21(11.000)^{\mathrm{b}}$ & $2.160 \pm 0.23(14.117)^{\mathrm{b}}$ \\
\hline
\end{tabular}

$\mathrm{IC}_{50}$ values are presented as the mean \pm standard deviation of three independent experiments performed in triplicate. FR was calculated as the ratio of $\mathrm{IC}_{50}$ of Adr in cells with or without WYE-354 to the $\mathrm{IC}_{50}$ of Adr in the parental cell line. ${ }^{\mathrm{a}} \mathrm{P}<0.05$ and ${ }^{\mathrm{b}} \mathrm{P}<0.005 \mathrm{vs}$. Adr control. $\mathrm{IC}_{50}$, concentration producing $50 \%$ decrease in cell viability; $\mathrm{FR}$, fold resistance; Adr, adriamycin.

A<smiles>COC(=O)Nc1ccc(-c2nc(N3CCOCC3)c(CN3CCN(C(=O)OC)CC3)nc2-c2ccco2)cc1</smiles>

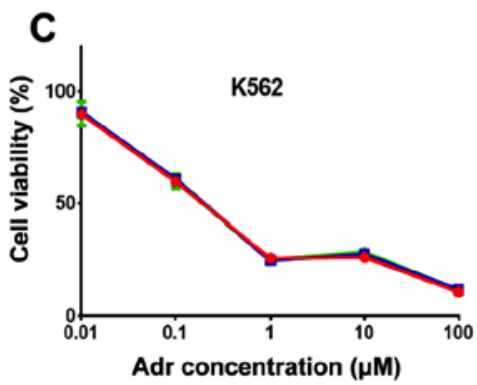

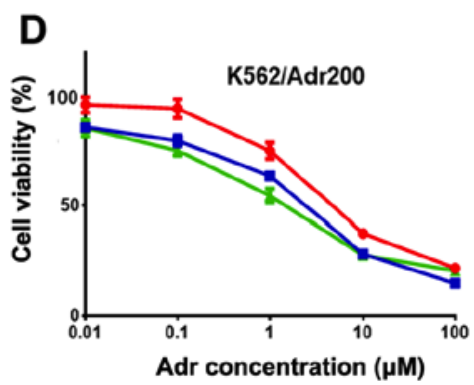
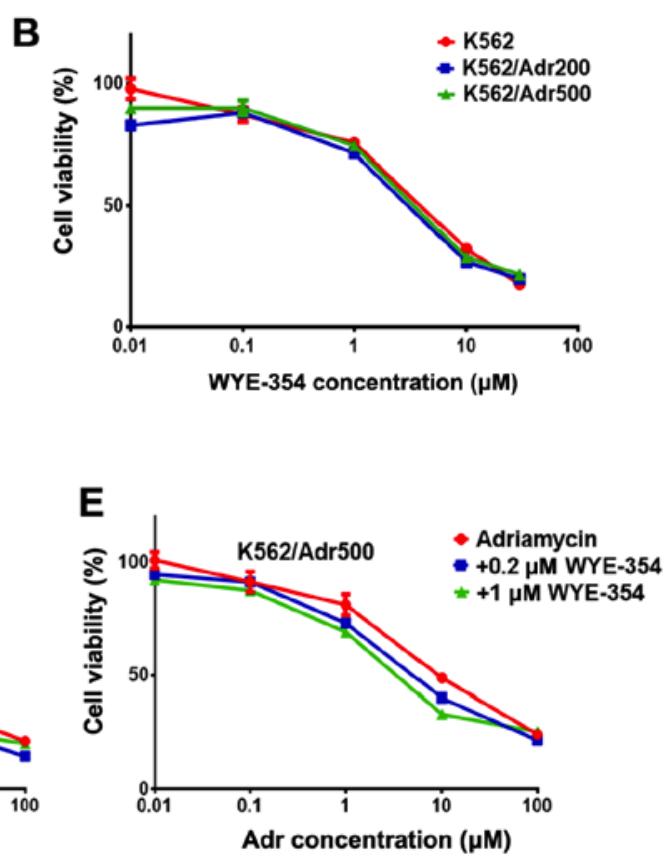

Figure 2. Effects of WYE-354 on Adr cytotoxicity in resistant cells. (A) Structure of WYE-354. (B) WYE-354 IC ${ }_{50}$ in the parent and resistant cell lines. Dose-response curves of (C) K562, (D) K562/Adr200 and (E) K562/Adr500 cells following treatment with $0.01-100 \mu \mathrm{M}$ Adr for $48 \mathrm{~h}$ in the presence of 0.2 and $1 \mu \mathrm{M}$ WYE-354, showing a decrease in $\mathrm{Adr} \mathrm{IC}_{50}$ in the Adr-resistant cell lines. Adr, adriamycin; $\mathrm{IC}_{50}$, concentration producing $50 \%$ decrease in cell viability.

significantly increased Adr cytotoxicity in both resistant cell lines by decreasing the $\mathrm{IC}_{50}$ from $2.5 \pm 0.3$ to $1.3 \pm 0.2 \mu \mathrm{M}$ in the K562/Adr200 cells and from $4.6 \pm 0.7$ to $1.7 \pm 0.3 \mu \mathrm{M}$ in the K562/Adr500 cells. Verapamil at $5 \mu \mathrm{M}$ was used as the positive control. Of note, Adr cytotoxicity in the parental K562 cells was unchanged by the addition of 0.2 or $1 \mu \mathrm{M}$ WYE-354, including the positive control (Table III). These results suggest that WYE-354 is a potent modulator of Adr resistance in vitro.

WYE-354 increases G2/M cell cycle arrest and apoptosis in combination with Adr in Adr-resistant cell lines. To elucidate the mechanism by which WYE-354 enhances Adr cytotoxicity in Adr-resistant cell lines, cell cycle analysis and apoptosis were assessed in the K562/Adr200 cells by flow cytometry. A viable dose of $200 \mathrm{nM}$ Adr, corresponding to $1 / 10$ of the $\mathrm{Adr} \mathrm{IC}_{50}$ for K562/Adr200 cells, was selected for the assays. As shown in Fig. 3A and B, treatment with 0.2 and $1 \mu \mathrm{M}$ WYE-354 did not produce any significant changes in the cell cycle distribution of K562/Adr200 cells, which was comparable to that in the untreated control, however, Adr at $200 \mathrm{nM}$ produced marked G2/M cell cycle arrest. The addition of $1 \mu \mathrm{M} \mathrm{WYE}-354$ to $200 \mathrm{nM}$ Adr caused a significant increase in G2/M cell cycle arrest in the K562/Adr200 cells. Similarly, $1 \mu \mathrm{M}$ WYE-354 significantly increased apoptosis in combination with $200 \mathrm{nM}$ Adr (Fig. 3C and D). No significant difference in apoptosis was observed upon treatment of the K562/Adr200 cells with WYE-354 or Adr alone.

WYE-354 inhibits R6G efflux in Adr-resistant cells. The effect of WYE-354 on the functional export of R6G, a known substrate of the ABCB1 protein pump, was evaluated by flow cytometry in K562 and K562/Adr200 cells in the presence of increasing concentrations of WYE-354. As shown in Fig. 4A and B, WYE-354 dose-dependently increased $\mathrm{R} 6 \mathrm{G}$ retention in the K562/Adr200 cells. The addition of 1,5 and $10 \mu \mathrm{M}$ WYE-354 increased R6G fluorescence in the K562/Adr200 cells from 
A

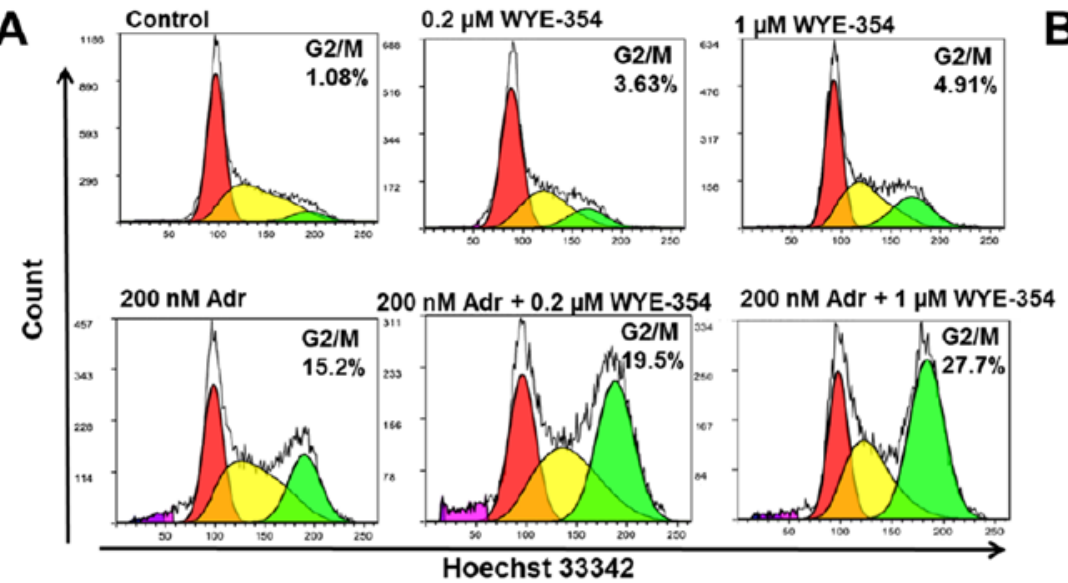

C

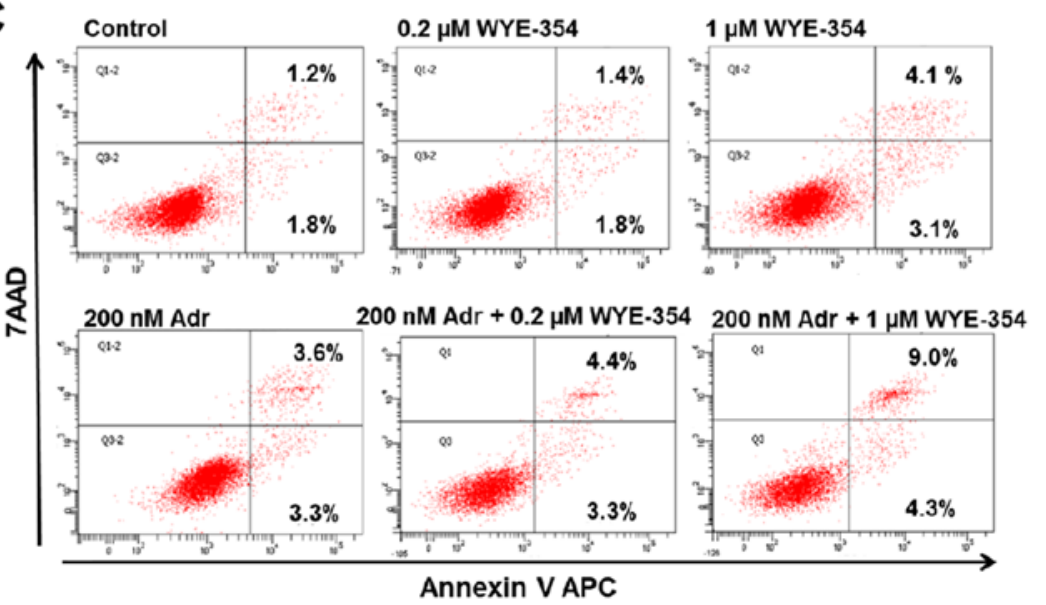

B

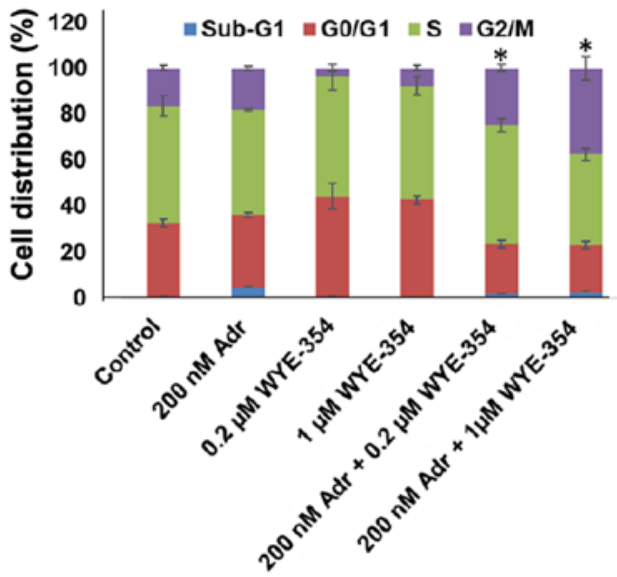

D

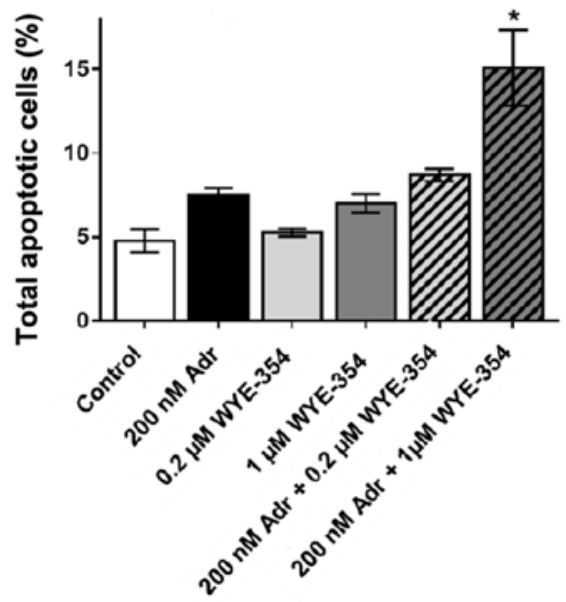

Figure 3. Effects of WYE-354 on cell cycle arrest and apoptosis in Adr-resistant cells. (A) Representative histogram of cell cycle analysis, performed with Hoechst 33342 staining by flow cytometry, for K562/Adr200 cells treated with indicated doses of WYE-354 alone or with $200 \mathrm{nM}$ Adr for $72 \mathrm{~h}$. (B) Mean percentage cellular distribution in different phases of the cell cycle plotted from three independent experiments performed in duplicate. Error bars indicate the standard error of the mean. (C) Representative histogram of apoptosis, assessed by Annexin V-APC-7AAD staining by flow cytometry in K562/Adr200 cells treated with $200 \mathrm{nM}$ Adr alone and in the presence of indicated doses of WYE-354 for $48 \mathrm{~h}$. (D) Mean percentage of total apoptotic cells following indicated treatments plotted from three independent experiments performed in duplicate. Error bars represent the standard deviation. ${ }^{*} \mathrm{P}<0.05 \mathrm{vs}$. Adr control. Adr, Adriamycin.

Table IV. R6G mean florescence intensity.

R6G mean florescence intensity

\begin{tabular}{llc}
\cline { 2 - 3 } Treatment & \multicolumn{1}{c}{ K562 } & K562/Adr200 \\
\hline Control & $39.336 \pm 3910$ & $1.663 .3 \pm 286.61$ \\
$1 \mu$ M WYE-354 & $40.561 \pm 401.5$ & $4.142 .5 \pm 1.216 .16^{\mathrm{a}}$ \\
$5 \mu \mathrm{M}$ WYE-354 & $41.636 \pm 499.5$ & $7.963 .25 \pm 664.47^{\mathrm{a}}$ \\
$10 \mu \mathrm{M}$ WYE-354 & $41.581 \pm 1,939.33$ & $25.690 .25 \pm 1.817^{\mathrm{a}}$ \\
$100 \mu \mathrm{M}$ verapamil & $48.137 \pm 450.6$ & $27.540 .36 \pm 609.1$
\end{tabular}

Data are presented as the mean \pm standard deviation of three independent experiments performed in duplicate. ${ }^{a} \mathrm{P}<0.05$ vs. control. R6G, rhodamine $6 \mathrm{G}$.

3.26 to $7.64,27.51$ and $56.54 \%$, respectively, relative to the K562 controls. Verapamil, a competitive ABCB1 inhibitor, was used as the positive control. No significant differences in R6G fluorescence emission was observed in the parental K562 cells following the addition of WYE-354 (Table IV). These findings clearly indicate that WYE-354 exerts an inhibitory effect on the ABCB1-mediated R6G efflux.

WYE-354 inhibits the activity of ABCB1-ATPase and does not regulate the protein expression of $A B C B 1$. To ascertain the molecular interaction of WYE-354 with the ABCB1 protein, an ABCB1-ATPase assay was performed. ABCB1 is an active transporter and the rate of ATP hydrolysis is a direct indicator of its activity. As shown in Fig. 5A, WYE-354 dose-dependently increased luminescence in cell fractions containing recombinant hABCB1 protein, suggesting that WYE-354 is a potent substrate of the ABCB1 pump. Verapamil, an $\mathrm{ABCB} 1$ substrate and a competitive inhibitor, was used as the positive control. Notably, WYE-354 exhibited sub-basal ABCB1 ATPase activity, corresponding to the quantity of ATP consumed, at concentrations $<1 \mu \mathrm{M}$ (Fig. 5B). This indicates that WYE-354 has an inhibitory effect on the ATPase activity of $\mathrm{ABCB} 1$ at low concentrations, which subsequently weakened as the WYE-354 concentration increased. A maximum increase by 3.45 -fold in the basal ATPase activity of $\mathrm{ABCB} 1$ was observed at a concentration of $50 \mu \mathrm{M}$, which was comparable to the increase produced by verapamil at 
A

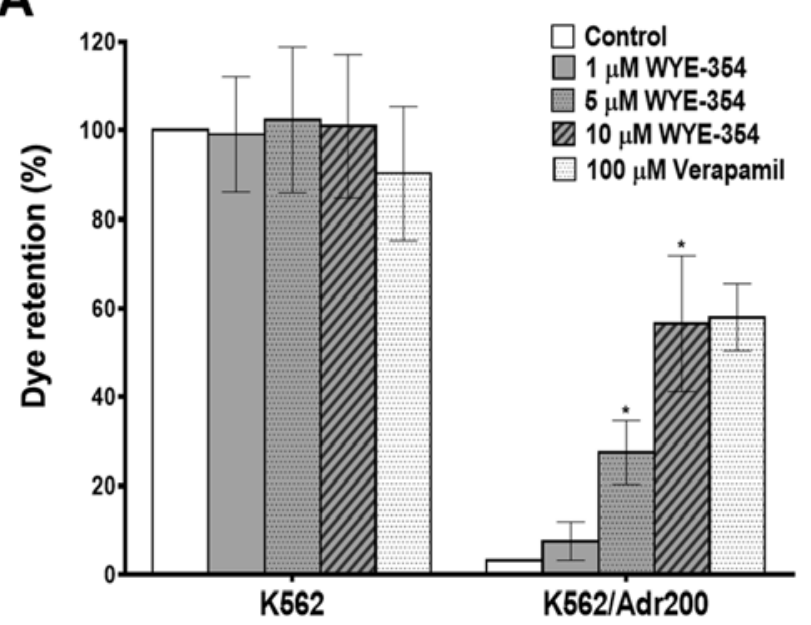

B

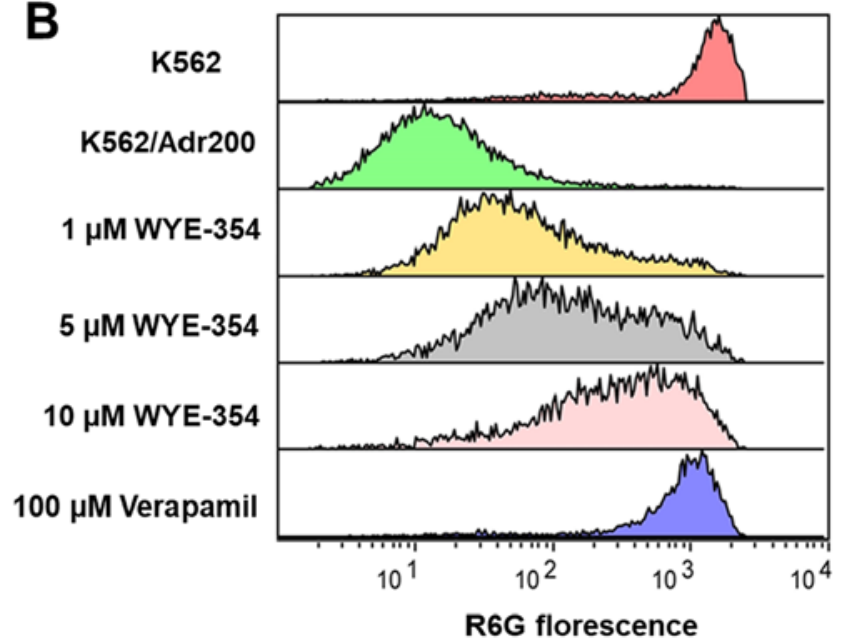

Figure 4. Effect of WYE-354 on R6G efflux in Adr-resistant cells. (A) R6G fluorescence depicted as \% dye retention compared with K562 cells (control). Data are presented as the mean \pm standard deviation of three independent experiments performed in duplicate. (B) Representative stacked histogram showing a dose-dependent increase of R6G florescence in K562/Adr200 cells when treated with 1, 5 and $10 \mu \mathrm{M}$ WYE-354 for 2 h. ${ }^{*} \mathrm{P}<0.05$ vs. untreated control. R6G, rhodamine 6G.
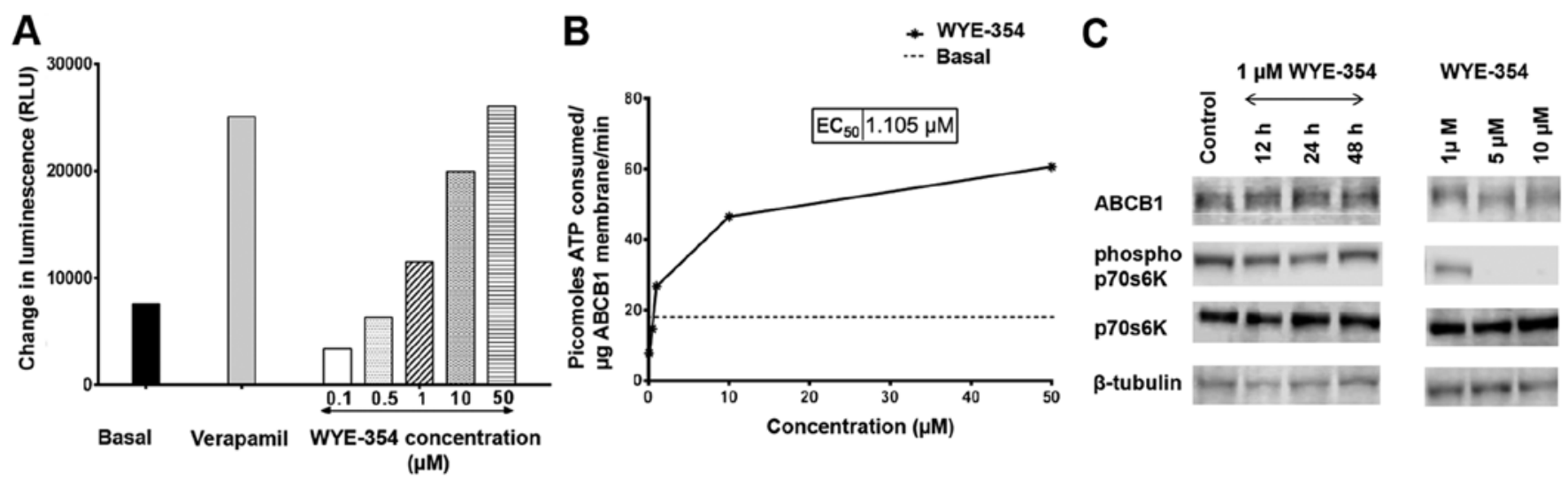

Figure 5. ABCB1-ATPase activity and protein expression of ABCB1. (A) Change in RLU of ABCB1 membranes when incubated in the presence of increasing doses of WYE-354 (0-50 $\mu \mathrm{M})$ and $500 \mu \mathrm{M}$ verapamil in triplicate for 60 min at $37^{\circ} \mathrm{C}$. (B) ATPase activity of ABCB1 as the quantity of ATP consumed demonstrated the stimulatory effect of WYE-354. (C) Western blot images showing difference in protein expression in K562/Adr500 cells when treated with $1 \mu \mathrm{M}$ WYE-354 for 12, 24 and $48 \mathrm{~h}$, and when treated with 5 and $10 \mu \mathrm{M}$ of WYE-354 for $24 \mathrm{~h}$. ABCB1, ABCB1, ATP-binding cassette subfamily B member 1.

Table V. Relative ABCB1 and p-p70S6K expression detected by western blots.

Normalized relative intensities as compared to control ${ }^{\mathrm{a}}$

\begin{tabular}{lcc}
\cline { 2 - 3 } Treatment & ABCB1 & p-p70S6K \\
\hline Control & 1 & 1 \\
$1 \mu \mathrm{M}$ WYE-354 $12 \mathrm{~h}$ & $0.82 \pm 0.09$ & $1.0 \pm 0.10$ \\
$1 \mu \mathrm{M}$ WYE-354 24 h & $0.95 \pm 0.12$ & $0.75 \pm 0.14$ \\
$1 \mu \mathrm{M}$ WYE-354 48 h & $1.22 \pm 0.13$ & $1.07 \pm 0.29$ \\
$1 \mu \mathrm{M}$ WYE-354 $(24 \mathrm{~h})$ & $1.22 \pm 0.50$ & $0.76 \pm 0.11$ \\
$5 \mu \mathrm{M}$ WYE-354 $(24 \mathrm{~h})$ & $1.02 \pm 0.26$ & $0.03 \pm 0.03^{\mathrm{b}}$ \\
$10 \mu \mathrm{M}$ WYE-354 $(24 \mathrm{~h})$ & $1.37 \pm 0.29$ & $0.04 \pm 0.04^{\mathrm{b}}$
\end{tabular}

${ }^{\mathrm{a}} \mathrm{ABCB} 1$ and $\mathrm{p}$-p70S6K intensities were normalized to $\beta$-tubulin and $\mathrm{p} 70 \mathrm{~s} 6 \mathrm{~K}$ respectively. Data are presented as the mean \pm standard deviation. ${ }^{\text {b}} \mathrm{P}<0.005$ vs. control.
$500 \mu \mathrm{M}$. Furthermore, western blotting revealed no significant differences in protein levels of ABCB1 in the K562/Adr500 cells following treatment with $1 \mu \mathrm{M}$ WYE-354 for 12,24 and $48 \mathrm{~h}$ time-points (Fig. 5C). At $1 \mu \mathrm{M}$, WYE-354 did not produce significant suppression of mTOR signaling, which was evident by the levels of p-p70S6K. Significant downregulation of p-p70S6K was observed only at high concentrations (5 and $10 \mu \mathrm{M}$ ), however, the protein expression of ABCB1 did not differ substantially from that exhibited by the untreated control, even at these concentrations (Table V). This indicates that WYE-354 did not regulate the expression of ABCB1 in the experiments.

WYE-354 shows high affinity for the hABCBI drug-binding pocket. The mechanistic interactions of WYE-354 at the drug-binding domain of the $\mathrm{ABCB} 1$ transmembrane protein were predicted by docking using a hABCB1 mouse homology model (Fig. 6A). As shown in Fig. 6B, WYE-354 exhibited high affinity for the drug-binding domain of hABCB1, interacting with several amino acid residues, primarily via hydrophobic 

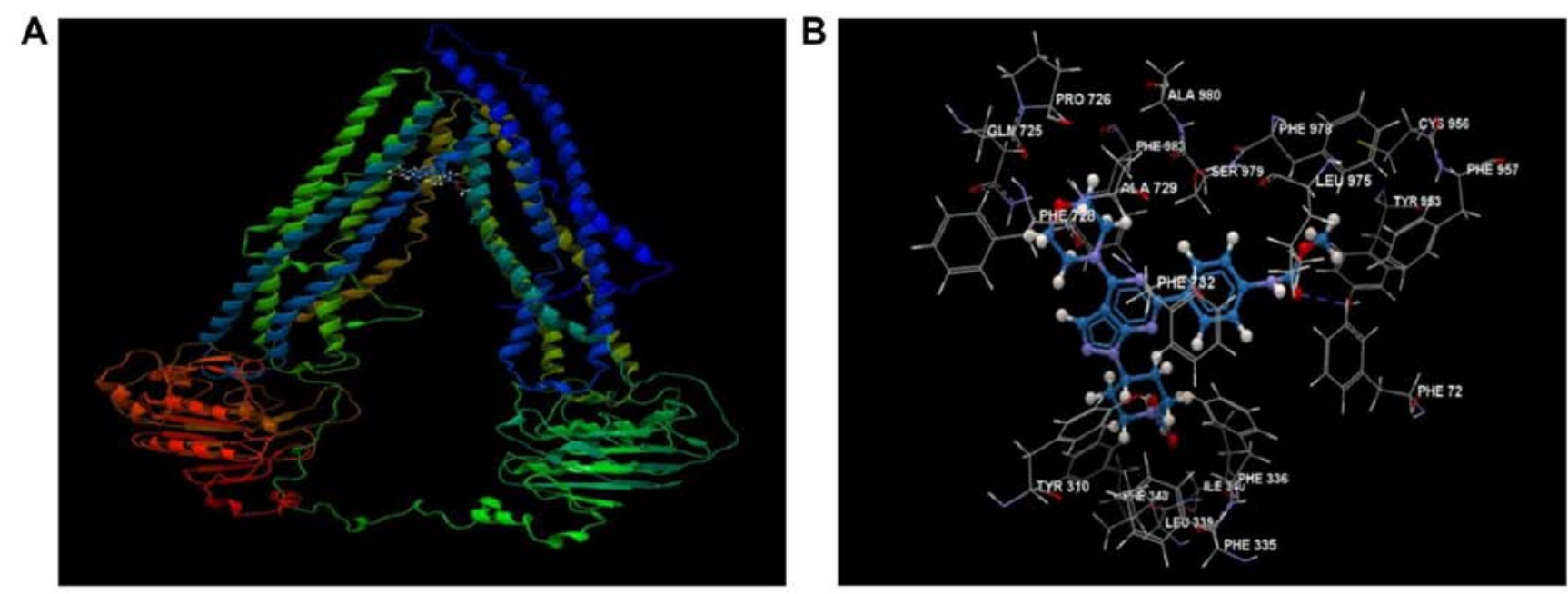

Figure 6. Affinity of WYE-354 to hABCB1. (A) WYE-354 interacting with the drug binding domain of the hABCB1 model. (B) WYE-354 stabilized by hydrophobic and steric interactions with amino acid residues in the drug binding domain of hABCB1. Hydrogen bonding is shown between WYE-354 and Tyr953 as a purple dashed line. hABCB1, recombinant human ATP-binding cassette subfamily B member 1 .

interactions, forming a prominent hydrogen bond with Tyr953. The overall binding and steric interaction scores, predicted using CLC Drug Discovery, for WYE-354 were -85.194 and -83.273, respectively, indicating that WYE-354 is a potent substrate of ABCB1.

\section{Discussion}

Despite advances in cancer research, chemotherapy remains the first-line treatment for AML, the efficacy of which is limited by the development of MDR. The overexpression of drug-efflux pumps has been implicated in the failure of AML chemotherapy, causing disease refraction or relapse (27). Therefore, substances that are capable of restoring chemosensitivity are continuously being investigated to maintain cytotoxicity and the clinical response of chemotherapeutics. The role of ABCB1 in mediating MDR in cancer cells has been extensively documented in different types of cancer. The overexpression of ABCB1 is associated with poor clinical response to chemotherapy in patients with AML (28). Therefore, the development or identification of safe and effective ABCB1 inhibitors is of particular interest. Besides specific inhibitors designed and developed to target $\mathrm{ABCB} 1$, a number of small molecule inhibitors targeting cellular signaling pathways have been demonstrated to interact with $A B C B 1$ as substrates or inhibitors. Various ABCB1 substrates may act as competitive inhibitors of $A B C B 1$ efflux activity $(8,29)$.

Aberrant PI3K/AKT/mTOR signaling is common in AML and is implicated in drug resistance $(30,31)$. First-generation mTOR inhibitors, including rapamycin and its analogs, have been previously reported to reverse resistance in different types of cancer $(32,33)$. Recently, BEZ235, a dual PI3K/mTOR inhibitor, demonstrated potent activity as a resistance-modifying agent in AML cell lines, where Adr-resistant K562 and vincristine-resistant HL60 cells were used to represent MDR in AML (34). The present study is the first, to the best of our knowledge, reporting the effects of the mTOR kinase inhibitor WYE-354 on restoring Adr chemosensitivity in MDR K562 cells in vitro. The present study evaluated the cytotoxicity of WYE-354 in combination with Adr in K562/Adr200 and K562/Adr500 cells. WYE-354 significantly sensitized the two MDR cell lines to chemotherapy by decreasing $\mathrm{Adr} \mathrm{IC}_{50}$. Importantly, $\mathrm{Adr}$ cytotoxicity remained unchanged in the parental cell line, suggesting that the mechanism may be associated with the acquisition of drug resistance. The fact that the overexpression of ABCB1 was identified as the mechanism underlying Adr resistance in K562/Adr200 and K562/Adr500 cells suggested that WYE-354 may be capable of interacting with the $\mathrm{ABCB} 1$ transporter, thus modulating its activity. Furthermore, the combination of WYE-354 and Adr caused increased apoptosis and G2/M cell cycle arrest, contributing to the increased chemosensitization of Adr-resistant cells.

Adr is a well-known substrate of ABCB1 and overexpression of the pump results in its increased clearance, thus preventing its intracellular accumulation and reducing its cytotoxicity as a consequence. The ABCB1 transporter activity was assessed based on the efflux of R6G, a florescent substrate of ABCB1. Detection of the natural florescence of rhodamine provides a robust screening platform for examining ABCB1 efflux and, unlike anthracyclines, quenching of florescence is not observed with rhodamine dyes (35). WYE-354 potently inhibited the efflux of R6G in Adr-resistant cells. This was consistent with the results from the cell viability assay, indicating that the observed chemosensitization towards Adr was in fact due to the inhibition of ABCB1-mediated Adr efflux, thus leading to an increased intracellular accumulation of Adr. Furthermore, WYE-354 dose-dependently increased the ATPase activity of ABCB1, indicating that it is a potent substrate of ABCB1. Notably, WYE-354 had a mild inhibitory effect on the ATPase activity of $\mathrm{ABCB} 1$ at low concentrations $(\leq 1 \mu \mathrm{M})$. This also partially explains why the observed $\mathrm{IC}_{50}$ of WYE-354, which was $>3.2 \mu \mathrm{M}$, did not differ markedly between the parental and resistant cell lines, as the substrate effect is expected to become significant only at high concentrations. The phosphorylation status of downstream targets directly reflects the potency of an inhibitor. The present study revealed that the 
concentration of WYE-354 required to re-sensitize resistant cell lines did not have an effect on the phosphorylation status of p70S6K, an effector molecule of the mTOR signaling pathway, even after $\leq 48 \mathrm{~h}$ of incubation. Furthermore, there was minimal effect on the protein expression of ABCB1 at high concentrations of WYE-354 $(10 \mu \mathrm{M})$. The molecular docking experiments revealed robust interactions of WYE-354 with the hABCB1 mouse homology model. The above findings suggest that the re-sensitization produced by WYE-354 is associated with the competitive inhibition of Adr efflux, as a result of WYE-354 being a substrate of ABCB1. These findings highlight WYE-354 as a potential resistance reversal agent, due to its interaction with the ABCB1 efflux pump, at the functional and molecular level.

In conclusion, the present study described a novel therapeutic application of the mTOR kinase inhibitor WYE-354 as a potent modulator of $\mathrm{ABCB} 1-$ mediated drug resistance. In addition, the interaction between WYE-354 and ABCB1 may significantly improve current understanding of drug availability and provide insights into possible drug interactions in combination therapies. The use of WYE-354 as a resistance-modulating agent can provide added benefit due to its intrinsic anticancer activity. Further investigations using patient-derived primary cell lines and animal models are warranted to validate the clinical applicability of using WYE-354 to potentially attenuate chemoresistance in vivo.

\section{Acknowledgements}

Not applicable.

\section{Funding}

The present study was funded by the National Plan for Science, Technology and Innovation (MAARIFAH), King Abdulaziz City for Science and Technology (grant no. 09-BIO693-03).

\section{Availability of data and materials}

The datasets and certain material used and/or analyzed during the present study are available from the corresponding author on reasonable request.

\section{Authors' contributions}

FA and AGC conceived and designed the experiments. SMI, AMI, SB and FA performed the experiments. Docking was performed and analyzed by PNP. SMI, FA and SK analyzed the data. SMI, and FA wrote the manuscript. JAK, AMA and MHAQ contributed with reagents/materials/analysis tools and critically revised the manuscript. All authors read and approved the final manuscript.

\section{Ethics approval and consent to participate}

Not applicable.

\section{Patient consent for publication}

Not applicable.

\section{Competing interests}

The authors declare that they have no competing interests.

\section{References}

1. Gottesman MM: Mechanisms of cancer drug resistance. Annu Rev Med 53: 615-627, 2002.

2. Shaffer BC, Gillet JP, Patel C, Baer MR, Bates SE and Gottesman MM: Drug resistance: Still a daunting challenge to the successful treatment of AML. Drug Resist Updat 15: 62-69, 2012.

3. Parkin B, Ouillette P, Li Y, Keller J, Lam C, Roulston D, Li C, Shedden K and Malek SN: Clonal evolution and devolution after chemotherapy in adult acute myelogenous leukemia. Blood 121: 369-377, 2013.

4. Löscher W and Potschka H: Role of drug efflux transporters in the brain for drug disposition and treatment of brain diseases. Prog Neurobiol 76: 22-76, 2005.

5. Mohammad IS, He W and Yin L: Understanding of human ATP binding cassette superfamily and novel multidrug resistance modulators to overcome MDR. Biomed Pharmacother 100: 335-348, 2018.

6. Dean M, Rzhetsky A and Allikmets R: The human ATP-binding cassette (ABC) transporter superfamily. Genome Res 11: 1156-1166, 2001.

7. Kathawala RJ, Gupta P, Ashby CR Jr and Chen ZS: The modulation of $\mathrm{ABC}$ transporter-mediated multidrug resistance in cancer: A review of the past decade. Drug Resist Updat 18: 1-17, 2015.

8. Binkhathlan Z and Lavasanifar A: P-glycoprotein inhibition as a therapeutic approach for overcoming multidrug resistance in cancer: Current status and future perspectives. Curr Cancer Drug Targets 13: 326-346, 2013.

9. Yang K, Chen Y, To KK, Wang F, Li D, Chen L and Fu L: Alectinib (CH5424802) antagonizes ABCB1- and ABCG2-mediated multidrug resistance in vitro, in vivo and ex vivo. Exp Mol Med 49: e303, 2017.

10. Zhang YK, Zhang GN, Wang YJ, Patel BA, Talele TT, Yang DH and Chen ZS: Bafetinib (INNO-406) reverses multidrug resistance by inhibiting the efflux function of ABCB1 and ABCG2 transporters. Sci Rep 6: 25694, 2016.

11. Qiu JG, Zhang YJ, Li Y, Zhao JM, Zhang WJ, Jiang QW, Mei XL, Xue YQ, Qin WM, Yang Y, et al: Trametinib modulates cancer multidrug resistance by targeting $\mathrm{ABCB} 1$ transporter. Oncotarget 6: 15494-15509, 2015.

12. Li J, Kumar P, Anreddy N, Zhang YK, Wang YJ, Chen Y, Talele TT, Gupta K, Trombetta LD and Chen ZS: Quizartinib (AC220) reverses ABCG2-mediated multidrug resistance: In vitro and in vivo studies. Oncotarget 8: 93785-93799, 2017.

13. Dos Santos C, Récher C, Demur C and Payrastre B: The PI3K/ $\mathrm{Akt} / \mathrm{mTOR}$ pathway: A new therapeutic target in the treatment of acute myeloid leukemia. Bull Cancer 93: 445-447, 2006 (In French).

14. Dinner S and Platanias LC: Targeting the mTOR Pathway in Leukemia. J Cell Biochem 117: 1745-1752, 2016.

15. Motzer RJ, Escudier B, Oudard S, Hutson TE, Porta C, Bracarda S, Grünwald V, Thompson JA, Figlin RA, Hollaender N, et al; RECORD-1 Study Group: Phase 3 trial of everolimus for metastatic renal cell carcinoma: Final results and analysis of prognostic factors. Cancer 116: 4256-4265, 2010.

16. Hudes GR, Berkenblit A, Feingold J, Atkins MB, Rini BI and Dutcher J: Clinical trial experience with temsirolimus in patients with advanced renal cell carcinoma. Semin Oncol 36 (Suppl 3): S26-S36, 2009.

17. Park S, Chapuis N, Saint Marcoux F, Recher C, Prebet T, Chevallier P, Cahn JY, Leguay T, Bories P, Witz F, et al; GOELAMS (Groupe Ouest Est d'Etude des Leucémies aiguës et Autres Maladies du Sang): A phase Ib GOELAMS study of the mTOR inhibitor RAD001 in association with chemotherapy for AML patients in first relapse. Leukemia 27: 1479-1486, 2013.

18. Haritunians T, Mori A, O'Kelly J, Luong QT, Giles FJ and Koeffler HP: Antiproliferative activity of RAD001 (everolimus) as a single agent and combined with other agents in mantle cell lymphoma. Leukemia 21: 333-339, 2007.

19. Grünwald V, DeGraffenried L, Russel D, Friedrichs WE, Ray RB and Hidalgo M: Inhibitors of mTOR reverse doxorubicin resistance conferred by PTEN status in prostate cancer cells. Cancer Res 62: 6141-6145, 2002. 
20. Wang Z, Huang $\mathrm{Y}$ and Zhang J: Molecularly targeting the PI3K-Akt-mTOR pathway can sensitize cancer cells to radiotherapy and chemotherapy. Cell Mol Biol Lett 19: 233-242, 2014.

21. Harrington LS, Findlay GM, Gray A, Tolkacheva T, Wigfield S, Rebholz H, Barnett J, Leslie NR, Cheng S, Shepherd PR, et al: The TSC1-2 tumor suppressor controls insulin-PI3K signaling via regulation of IRS proteins. J Cell Biol 166: 213-223, 2004.

22. Sun SY: mTOR kinase inhibitors as potential cancer therapeutic drugs. Cancer Lett 340: 1-8, 2013.

23. Yu K, Toral-Barza L, Shi C, Zhang WG, Lucas J, Shor B, Kim J, Verheijen J, Curran K, Malwitz DJ, et al: Biochemical, cellular, and in vivo activity of novel ATP-competitive and selective inhibitors of the mammalian target of rapamycin. Cancer Res 69: 6232-6240, 2009.

24. Wang L, Zhu YR, Wang S and Zhao S: Autophagy inhibition sensitizes WYE-354-induced anti-colon cancer activity in vitro and in vivo. Tumour Biol 37: 11743-11752, 2016.

25. Weber H, Leal P, Stein S, Kunkel H, García P, Bizama C, Espinoza JA, Riquelme I, Nervi B, Araya JC, et al: Rapamycin and WYE-354 suppress human gallbladder cancer xenografts in mice. Oncotarget 6: 31877-31888, 2015.

26. Livak KJ and Schmittgen TD: Analysis of relative gene expression data using real-time quantitative PCR and the 2(-Delta Delta C(T)) method. Methods 25: 402-408, 2001.

27. Salvia AM, Cuviello F, Coluzzi S, Nuccorini R, Attolico I, Pascale SP, Bisaccia F, Pizzuti M and Ostuni A: Expression of some ATP-binding cassette transporters in acute myeloid leukemia. Hematol Rep 9: 7406, 2017.

28. Liu B, Li LJ, Gong X, Zhang W, Zhang H and Zhao L: Co-expression of ATP binding cassette transporters is associated with poor prognosis in acute myeloid leukemia. Oncol Lett 15: 6671-6677, 2018.
29. Beretta GL, Cassinelli G, Pennati M, Zuco V and Gatt L: Overcoming ABC transporter-mediated multidrug resistance: The dual role of tyrosine kinase inhibitors as multitargeting agents. Eur J Med Chem 142: 271-289, 2017.

30. Martelli AM, Evangelisti C, Chiarini $F$ and McCubrey JA: The phosphatidylinositol 3-kinase/Akt/mTOR signaling network as a therapeutic target in acute myelogenous leukemia patients. Oncotarget 1: 89-103, 2010

31. Tabe Y, Tafuri A, Sekihara K, Yang H and Konopleva M: Inhibition of mTOR kinase as a therapeutic target for acute myeloid leukemia. Expert Opin Ther Targets 21: 705-714, 2017.

32. Ying L, Zu-An Z, Qing-Hua L, Qing-Yan K, Lei L, Tao C and Yong-Ping W: RAD001 can reverse drug resistance of SGC7901/DDP cells. Tumour Biol 35: 9171-9177, 2014.

33. Ma Q, Chang Z, Wang W and Wang B: Rapamycin-mediated mTOR inhibition reverses drug resistance to adriamycin in colon cancer cells. Hepatogastroenterology 62: 880-886, 2015.

34. Deng L, Jiang L, Lin XH, Tseng KF, Liu Y, Zhang X, Dong RH, Lu ZG and Wang XJ: The PI3K/mTOR dual inhibitor BEZ235 suppresses proliferation and migration and reverses multidrug resistance in acute myeloid leukemia. Acta Pharmacol Sin 38: 382-391, 2017.

35. Lee JS, Paull K, Alvarez M, Hose C, Monks A, Grever M, Fojo AT and Bates SE: Rhodamine efflux patterns predict P-glycoprotein substrates in the National Cancer Institute drug screen. Mol Pharmacol 46: 627-638, 1994.

This work is licensed under a Creative Commons Attribution-NonCommercial-NoDerivatives 4.0 International (CC BY-NC-ND 4.0) License. 